\title{
Pollutant formation and emissions from cement kiln stack using a solid recovered fuel from municipal solid waste
}

\author{
Juan A. Conesa*, Lorena Rey, Silvia Egea, Maria D. Rey \\ Chemical Engineering Department. University of Alicante. P.O. Box 99, 03080 \\ Alicante (Spain). Phone: +(34) 965903867 Fax: +(34) 965903826 \\ Author email address: ja.conesa@ua.es
}

\section{ABSTRACT}

The thermal decomposition of a Solid Recovered Fuel (SRF) has been studied by two techniques. First, laboratory-scale experiments were performed in a horizontal furnace in which different atmospheres are studied to analyze the dioxins and furans (PCDD/Fs) evolved from the decomposition of the material. Sulfur presence is revealed to be important in PCDD/Fs formation. In the second technique, the emission of various pollutants (PAHs, PCDD/Fs, metals, acid gases ...) were determined in a cement kiln fed on different proportions of SRF material, and where a maximum feed rate of 15000 $\mathrm{kg} \mathrm{SRF} / \mathrm{h}$ was achieved. In the laboratory furnace the dioxin toxicity revealed a maximum when the amount of oxygen in the atmosphere increased until approximately stoichiometric conditions. In the cement kiln, all emitted pollutants are under the legal limits. No correlation between SRF input and metal emission was observed.

Keywords: dioxin, heavy metals, municipal solid waste, emission, cement kiln, waste, co-combustion 


\section{INTRODUCTION}

Waste management is defined as the set of operations to give the waste produced in a particular area the most appropriate destination from an economic and environmental point of view, according to their characteristics, volume, source, recovery and marketing opportunities, cost treatment and legal regulations.

The use of solid wastes as supplementary fuel or as raw material substitute in cement kilns is one of the best technologies for a complete and safe destruction of wastes, due to the fact that there is a simultaneous benefit of destroying wastes and producing energy. Nevertheless, some wastes, such as those containing an important amount of $\mathrm{Hg}$, should be carefully treated in the kiln. At the same time, substituting primary fossil fuels has environmental and economic advantages. The main benefits of using solid wastes in cement kilns include energy recovery, conservation of nonrenewable fuels, reduction in cement production costs and the use of pre-existing facilities.

Types of wastes presently used as supplementary fuel by the cement industry include paint thinners, degreasing solvents, solvents from ink and printing industries, chemical byproducts from pharmaceutical and chemical manufacturing, waste oils, waste tires, municipal solid wastes, sewage sludge and waste timbers. Although they are actually burned, the thermal decomposition of such wastes has not been in some cases studied from a scientific point of view until recently. Under adequate conditions, waste materials such as tyres, oils, municipal solid waste and solvents can be used as supplementary fuel in cement plants. Concrete can be used for encapsulation of waste materials such as tyres, plastics and glasses [1].

Solid Recovered Fuel (SRF) is a waste derived fuel made from non-hazardous household waste. SRF is the non-recyclable fraction of municipal waste and consists of approximately $30 \%$ paper, $20 \%$ wood, $35 \%$ plastic and $15 \%$ textile waste [2]. It is a lightweight material with less than $20 \%$ moisture and formed by fragments of about 4 $\mathrm{cm}$. SRF is more homogeneous and less contaminated than the generic refuse derived fuel (RDF) [2]. It is being tested as an alternative fuel for cement industry, but its 
calorific value is much lower than the petroleum coke, so that to achieve high energy substitutions a great deal of SRF must be fed into the kiln in comparison with conventional fuels. A thermodynamic analysis provides insight into the technical and environmental feasibility of cocombusting SRF in coal-fired power plants and cement kilns. Results indicate the use of SRF as co-fuel can reduce global warming and acidification potential significantly [2].

$\mathrm{RDF}$ has been analysed as a possible sustitute to petroleum coke in cement industry [3]. In this context, technical, economical and social assessments have been done for the RDF utilization in cement industry.

The SRF should have some characteristics in order to be used as a fuel for cement kilns [2]. The most widely used standard is the CEN/TC 343 regulation. It stipulates several kinds of SRF depending on its calorific power and the presence of different pollutants, chlorine and mercury among them, being both very important parameters in the operation of cement factories.

The most important characteristics of SRF destined to the cement sector are: High calorific power, about 16-18 MJ/kg (although some clinker plants demand higher values); Reduced amount of chlorine (inferior to $0.5 \%$ ); Reduced amount of mercury (inferior to $10 \mathrm{mg} / \mathrm{kg}$, on a dry base). This specification corresponds to high quality SRF, based on the CEN/TC 343 regulation (European Committee for Standardization). In order to be able to comply with the emission restrictions established by the legislation, the most important limitations are related to chlorine content, to manage the installation in a stable state, as well as mercury and the presence of heavy metals in the SRF.

It has been reported [4] that the substitution of traditional fossil fuels in cement kilns by SRF does not increase the levels of heavy metals and PCDD/Fs in the vecinity of the plant. The carcinogenic and non-carcinogenic risks derived from exposure to metals and PCDD/Fs for the population living in the vicinity of the facility were within the ranges considered as acceptable according to national and international standards[4].

In the present paper the thermal decomposition of a SRF destined to the cement industry was studied. It has been performed using a laboratory horizontal furnace in order to get information about the amount of PCDD/Fs that can be formed and the 
conditions in which they are formed. Furthermore, the SRF has been used as an alternative fuel in a cement kiln with feed rates in the range of $0-15000 \mathrm{~kg} / \mathrm{h}$, and the emissions of various pollutants have been measured using standard methods. Dioxins and furans (PCDD/Fs), polycyclic aromatic hydrocarbons (PAHs), heavy metals (HM), and acidic gases $(\mathrm{HCl}, \mathrm{HF})$ were analyzed according to standard methods of sampling and determination. Tests in the cement kiln were performed for more than one year, because of the difficulty of the work done. A similar study was done using sewage sludge and tires in the same cement kiln [5].

\section{MATERIALS AND METHODS}

\section{SRF characterization}

The SRF used for the development of this work was provided by the company CEMEX ESPAÑA S.A. and was obtained from three different suppliers. The SRF has a split appearance, with diverse colors due to the heterogeneity in its composition. It has also a strong unpleasant odor. Prior to the characterization of the material, representative amounts of the three samples were mixed, homogenized and ground to an average size of $1 \mathrm{~mm}$. Analyses were performed on this representative sample of the waste (see the results in Table 1).

Elemental analysis was performed by oxidation of the sample at $1000{ }^{\circ} \mathrm{C}$ and subsequent detection of combustion products $\left(\mathrm{CO}_{2}, \mathrm{H}_{2} \mathrm{O}, \mathrm{N}_{2}\right.$ and $\left.\mathrm{SO}_{2}\right)$. The equipment used was a Perkin-Elmer 2400 (Perkin-Elmer, UK). Net Calorific Value (NCV) was determined using a calorimetric bomb AC-350 Leco Instruments. Biomass content was determined by analyzing the content of hemicellulose, cellulose and lignin, according to Rowell et al. [6] and test methods T12, T222 and T203 of the "Technical Association for the Pulp and Paper Industries" [7-9]. For metal analysis, the sample was diggested according to EPA Method 3050B, and the analysis was performed by ICP/MS. Anions $\mathrm{Cl}^{-}$and $\mathrm{SO}_{4}{ }^{-2}$ : EPA Methods 5050 and 9056 using an ionic chromatograph DIONEX DX500. Analysis of PCDD/Fs was performed according to EPA method 1613 and analysis of PAHs (polycyclic aromatic hydrocarbons) by gas chromatography-mass spectrometry. 


\section{Horizontal Furnace}

The equipment used to carry out the present work, shown in Figure S1 in the Supporting Information, has been exclusively developed to accurately control the ratio of oxygen in combustion processes. It consisted of a moving tubular reactor with the SRF carefully placed along the tube (SRF is placed in four boats of $7 \mathrm{~cm}$ each), which is introduced at a precisely controlled speed to a furnace while a constant flow of gas is passing through. More details of the equipment can be found elsewhere [10]. A resin trap containing Amberlite ${ }^{\circledR}$ XAD-2 resin was placed at the exit of the system for pollutant retention. At the end of the experiments, a solid residue is present in the tube, corresponding to the non volatilizable part of the SRF in the experimental conditions.

\section{Cement Kiln Emissions}

The methods used for the sampling and the analysis are standard methods suggested by the Spanish regulations for stack analysis. The methods used were previously reported [5]. Almost all of these methods require an isokinetic regime for gas sampling. The isokinetic sampling equipment was an APEX INSTRUMENTS system, model SKMM5HS. PCDD/Fs require around eight hours of sampling time and the analysis was carried out by high-resolution gas chromatography coupled to a high-resolution mass spectrometer (HRGC/HRMS). PAHs sampling and extraction was done in the same sample than PCDD/Fs. PAHs were analysed by low resolution mass spectrometry using deuterated isomers, as explained in other contributions $[11,12]$. Other details of the analysis of the emissions can be found in previous work [5].

For PCDD/Fs analysis, quality control and assurance criteria were based on the minimum requirements described in method EPA 1613 (accurate isomer-specific GC separation, sensitivity check and 10000 resolution power of HRMS, right recoveries, etc). Moreover, other quality control measures such as the analysis of blanks, analysis of certified reference materials, and participation in intercalibration exercises were performed. 


\section{Operating conditions of the runs (lab)}

Runs have been performed by introducing the SRF to the furnace at four linear velocities, and then obtaining four ratios of oxygen calculated using the following relationship:

$$
\lambda=\frac{\left(m_{\mathrm{O}_{2}}\right)_{\text {actual }}}{\left(m_{\mathrm{O}_{2}}\right)_{\text {stoic }}}=\frac{m_{\text {air }} \cdot 23}{\frac{m_{\text {sample }} \mathrm{V}}{L}\left(\frac{\% C}{12}+\frac{\% H}{4}+\frac{\% S}{32}-\frac{\% O}{32}\right) \cdot 32}
$$

where:

$\% \mathrm{O}, \% \mathrm{H}, \% \mathrm{~S}, \% \mathrm{C}=$ weight percentage of oxygen, hydrogen, sulphur and carbon in the $\mathrm{SRF}$

$\mathrm{m}_{\text {air }}=$ air flow rate $(\mathrm{kg} / \mathrm{s})$

$\mathrm{m}_{\text {sample }}=$ weight of the residue $(\mathrm{kg})$

$\mathrm{L}=$ length of tube occupied by the residue $(\mathrm{m})$

$v=$ linear velocity of introduction of the tube $(\mathrm{m} / \mathrm{s})$

A value of $\lambda$ lower than one involves combustion in sub-stoichiometric conditions while values of $\lambda$ higher than unity represent excess air.

The specific conditions of the runs were: $1.0 \mathrm{~g}$ of SRF, air flow rate $300 \mathrm{~mL} / \mathrm{min}$. The temperature used was $850{ }^{\circ} \mathrm{C}$ in the combustion oven. Velocities and subsequent oxygen ratios: $0.3 \mathrm{~mm} / \mathrm{s}(\lambda=1.48), 0.5 \mathrm{~mm} / \mathrm{s}(\lambda=1.02), 1.1 \mathrm{~mm} / \mathrm{s}(\lambda=0.51), 1.8 \mathrm{~mm} / \mathrm{s}$ $(\lambda=0.29)$. In each run PCDD/Fs were determined.

Temperature of the actual decomposition of SRF and interaction with the hot gases is not known. The interaction takes place somewhere between the gas exit of the cement kiln (approx. $1500^{\circ} \mathrm{C}$ ) and the input of the meal solids (approx. $300{ }^{\circ} \mathrm{C}$ in the preheater). In the present study an intermediate temperature of $850{ }^{\circ} \mathrm{C}$ has been selected. In previous studies [13], maximum yield of pollutants is observed at a nominal temperature between 700 and $800^{\circ} \mathrm{C}$, when working with meat and bone meal wastes. 


\section{Evolution of PCDD/Fs}

The evolution of the emission of dioxins and furans at the different experimental conditions is shown in Figure 1. Note that in this Figure the most abundant congener (23478 PeCDF) is shown in a different y-axis. Table S1 in the Supporting Information provides the complete data of the analyses done. Profiles shown in Figure 1 are those typical in combustion processes [14-16], with a higher amount of furans than dioxins.

Figure 1 also shows that the emission of PCDD/Fs (partially oxygenated compounds) presents a maximum at quasi stoichiometric conditions $(\lambda=1)$. This indicates that the formation of such pollutants is promoted at intermediate oxygen conditions, as already shown when working with another material [17]. An oxygen excess promotes the destruction of possible PCDD/Fs formed, as it occurs with other compounds [11, 18, 19]. It is remarkable that in poor oxygen atmosphere $(\lambda=0.29)$ their production is not neligible. Data in Figure 1 represent values of total emissions of 115, 300, 2790 and 775 pg I-TEQ/g SRF at values of $\lambda=0.29,0.51,1.02$ and 1.48 respectively.

\section{[Figure 1]}

Therefore, it can be concluded that not only the nature of the waste can influence the production of $\mathrm{PCDD} / \mathrm{Fs}$, but also the amount of oxygen in the media should be adequate.

This result is important for industrial furnaces that could have zones with poor oxygen mixture. In these zones low oxygen ratios are present and the production of dioxins could occur.

The decomposition of sewage sludge previously studied [17] present similar behaviour, but in this case the maximum in the formation of PCDD/Fs was found at conditions in which $\lambda$ is close to 0.7 . Differences found in both materials could be due:

- On the one hand, to the different concentrations of precursors found in both materials. Comparing the maximum amount of PCDD/Fs obtained with SRF and sewage sludge great differences can be observed: approx. $150 \mathrm{pg} / \mathrm{g}$ of a single congener in the sewage sludge combustion, while in the case of SRF it has been found approx. $4000 \mathrm{pg} / \mathrm{g}$. 
- The amount of chlorine measured in both samples is similar and close to 2000 $\mathrm{mg} / \mathrm{kg}$. But it is remarkable that the amount of $\mathrm{SO}_{4}{ }^{2-}$ found in the SRF is much lesser than that measured in the case of sewage sludges $(12408 \mathrm{mg} / \mathrm{kg}$, as reported in [17]). Some authors [20, 21] reveal that the presence of sulphur inhibited the formation of dioxins and furans, mainly through $\mathrm{SO}_{2}$ repletion on $\mathrm{Cl}_{2}$. This should explain the low amount of PCDD/Fs formed in the combustion of sewage sludges compared to SRF.

The most abundant congener found in all runs has been 23478-PeCDF, which has been identified as the most representative of the emissions of municipal solid waste incineration [22]. The same congener has been the most abundant in previous studies about the decomposition of sewage sludge, PVC and textile wastes [14].

\section{EMISSION IN THE CEMENT KILN STACK}

\section{Operating conditions of the runs (cement kiln)}

Five series of runs (Series 'A' to 'E') were carried out with different mass flows of SRF. First, a blank series was scheduled in order to have an idea of the levels of pollutants emitted with no feeding of the new waste. In the blank A-series the fuels used were petroleum coke, tires and meat-bone meals. Once the cement plant began to introduce SRF the amount was growing in different periods of time, taking samples at approx. 15, 25, 40 and $70 \%$ of the energy produced by SRF. In each series, the sampling of each kind of pollutants was done three different days: one day for HM sampling, another day for dioxin and PAHs sampling and a third day for gas and $\mathrm{HCl}+\mathrm{HF}$ sampling. Table 2 presents the amount of fuels fed to the furnace in each series. Three different days were necessary for each series because of the time spent during sampling.

It is important to note that the points where fuels are added to the kiln are different according to its nature: whereas the petroleum coke is added in the main burner, the waste tyres are fed at the other side, in the point where cement raw material goes into the kiln. In addition, sewage sludges, meat-bone meals and SRF are also fed in the main burner with petroleum coke. This is due to the cement factory uses a combustion technology equivalent to the combustion by stages to decrease the NOx emissions. 


\section{[Table 2]}

Some parameters were continuously monitored in each sampling. Table 3 shows the average values and standard deviations of these parameters in each sampling series. Note that the amount of oxygen is lower in the intermediate substitution levels (series C), coinciding with the highest emission of carbon monoxide. $\mathrm{NO}_{\mathrm{x}}$ emission seems to decrease with increasing amounts of SRF, indicating that maybe temperature in the oven decreases as SRF is introduced. $\mathrm{SO}_{2}$ decrease when increasing SRF was due to the lower amounts of petroleum coke introduced to the furnace, lowering the amount of sulphur present in the oven and the emissions.

\section{[Table 3]}

The latest legal reference that allows us to make a presentation of the results with comparative emission values is the "Directive 2000/76/EC of the European Parliament and the Council of $4^{\text {th }}$ December 2000 on the incineration of waste". This directive sets out the measures that must be met by the incineration plants to maintain a high degree of protection to the environment and human health. The legal limits could be found in the Directive and also in previous work [5].

\section{PCDD/Fs emission}

Figure 2 shows the results of the emission of each of the 17 congeners analyzed. The recovery factor was higher than $80 \%$ for all the congeners in the analyses. The data presented corresponds to the whole sampling (two different fractions are analyzed in each sampling, one for the particulate filter and other for the XAD-2 resin).

\section{[Figure 2]}

These results represent emissions of 4.49, 4.42, 8.48, 5.53 and $5.07 \mathrm{pg}$ I-TEQ/ $/ \mathrm{Nm}^{3}$ for series A to E, respectively. The analyses gave a level of dioxins emitted much lower than that permitted (max. $100 \mathrm{pg}$ I-TEQ $\mathrm{Nm}^{-3}$ ). This is common to other factories in Spain, as reported [4, 23-25]. Some papers in literature also reported no increase of dioxin emissions with the use of an alternative fuel [5, 20, 23, 25]. 
The congener profile obtained is typical of environmental samples with a predominance of hepta and octachlorinated congeners, for both dioxins and furans [16]. The different concentrations of PCDD/Fs obtained in each sampling series, together with the corresponding percentage of petroleum coke, tires, MBM, sewage sludge and $\mathrm{SRF}$ were subjected to a principal component analysis. The results of the PC analysis are shown in Figure S2 in the Supporting Information. In Figure S2 it can be observed that a great majority of PCDD/Fs congeners correlate with the \% of PetCoke fed to the cement kiln. \% Sludge and \% SRF are related with the emission of some furan congener (OCDF and 2378TCDF), whereas \% MBM seems to be independent from any PCDD/Fs emission. Also correlations between the emission of different pollutants have been analysed following the method proposed by Oh et al. [26]. The results show that only the emissions of vanadium, cadmium, napthalene and acenaphthene have a positive correlation $\left(\mathrm{R}^{2}>0.7\right)$ with total dioxin toxic equivalent emission.

Wurst and Prey [27] and Karstensen [20] indicated that the material used as fuel in industrial furnaces was not responsible for the dioxin emissions. The conditions of the furnace (very high temperature, good mixing and excess oxygen) make the cement kiln factory an ideal place to get a very good combustion. Some papers reported that the amount of organic matter in the cement raw material seems to be responsible for the possible changes in emissions of organic compounds [28-30]. This is because a small proportion of the organic compounds featuring natural materials could volatilize along the kiln system at temperatures between 400 and $600{ }^{\circ} \mathrm{C}$, i.e., the preheating zone, by contacting the raw material feed with gases from the clinker furnace [25].

\section{Polycyclic aromatic hydrocarbons (PAHs)}

The PAHs analyzed are the sixteen designated by the U.S. EPA as priority pollutants, although there are only six that are considered carcinogenic by the WHO (Benzo(a)anthracene, Benzo(b)fluoranthene, Benzo(k)fluoranthene, Benzo(a)pyrene, Dibenzo(ah)anthracene, Indene (1,2,3-cd) pyrene). The results are shown in Figure 3.

[Figure 3]

A detailed study of PAH emission from various industrial stacks has been done [31]. In this study, similar levels of PAHs were found in cement factories; the authors indicate 
that the use of heavy oil as fuel induced the formation of higher 4, 5, 6 and 7-ring aromatics. In the present study, not so heavy hydrocarbons are found.

No significant differences were found in the samples collected. The legal limit for total organic carbon (TOC) is $10 \mathrm{mg} / \mathrm{Nm}^{3}$. PAHs compounds analyzed are part of the TOC, as it was observed that their contribution in the emission of TOC is very small.

\section{Hydrogen chloride and fluoride}

The results of HF emission indicated that all samples collected were not detectable in the analytical procedure. Bearing in mind the detection limit, it can be concluded that all samples are approx. $<0.1 \mathrm{mg} / \mathrm{Nm}^{3}$.

In the case of $\mathrm{HCl}$, the results are $1.8,0.2,0.7,2.1$ and $3.7 \mathrm{mg} / \mathrm{Nm}^{3}$ for series A to $\mathrm{E}$ respectively. All values found are lower than those permitted by EU laws. It is worth to note that in sampling series "E" the value found for $\mathrm{HCl}$ was much higher than obtained in the other series, coinciding with the highest SRF feed rate.

\section{Heavy metals}

Figure 4 shows the heavy metal emission results. The data presented corresponds to the whole sampling (four different fractions are analyzed in each sampling, following the EPA method). Data for metal emission corroborates that in any case the legal limits were not reached. The emitted amount of $\mathrm{Zn}$ and $\mathrm{Mn}$ were the highest found and the most problematic. Bearing in mind the high $\mathrm{Zn}$ and Mn content of the SRF, it seemed that these metals were not being satisfactorily fixed in the cement kiln. In order to find more evidence of behavior similarities a multivariate analysis was also performed for HM emissions. The different concentrations of metals obtained in each sampling series, together with the corresponding percentage of petroleum coke, tires, MBM, sewage sludge and SRF were subjected to a principal component analysis. The data was not autoscaled before PC analysis. The results of the PC analysis are shown in Figure 5. The first PC (48.2\% of variance) was positively correlated with concentrations of $\mathrm{Cr}, \mathrm{Ni}$, $\mathrm{Zn}, \mathrm{Sn}$ and $\mathrm{Sb}$ and with the \% sludge and \% SRF in the cement kiln but not the concentration of Mn. The second PC (26.0\% of variance) was correlated with yields of $\mathrm{Mn}, \mathrm{Co}, \mathrm{Ni}$, As and with the $\%$ of sludge and \% meat-bone meals. 
Altough $\mathrm{Zn}$ emission and \% SRF are positively correlated with PC1, it is necessary that both parameters have similar coeficients in PC1 and PC2 to be related one to another (i.e. when representing PC2 vs. PC1 they should be close in the same group). This is not the case for $\mathrm{Zn}$ emission and \% SRF, in such a way that they are not related.

[Figure 4]

[Figure 5]

Achternbosh et al. [32] were more concerned about the quality of the cement itself when using alternative fuels. They found an increase in the trace element concentration of cement due to the use of waste as an input material for antimony, cadmium and zinc. Also lead and cobalt concentrations increased in the cement, but this increase was less pronounced. The authors indicated that contrary to trace elements from raw materials, trace elements from fuels underwent an additional resistance in the heat exchanger/rotary kiln system, as a result of which their probability of being emitted was much smaller.

\section{COMPARISON BETWEEN RUNS PERFORMED IN THE LABORATORY HORIZONTAL FURNACE AND THE EMISSIONS IN THE CEMENT KILN}

The data of the production of $\mathrm{PCDD} / \mathrm{Fs}$ in the laboratory horizontal reactor cannot, obviously, be directly extrapolated to the cement kiln situation. It has been observed that the important aspects influencing PCDD/Fs emission in an incinerator are combustion conditions and air pollution control (APC) devices installed [33-35].

Nevertheless, the present study permits the calculation of the possible maximum amounts of such pollutants that can be released from the oven. For the calculation the the following data [36] for the cement plant was assumed: SRF average feed rate: 10000 $\mathrm{kg} / \mathrm{h}$, average clinker production: $120000 \mathrm{~kg} / \mathrm{h}$, average volume of evolved gases (estimated): $290000 \mathrm{Nm}^{3} / \mathrm{h}$. If approx. $2000 \mathrm{ng} \mathrm{I-TEQ/kg} \mathrm{SRF} \mathrm{are} \mathrm{produced,} \mathrm{a}$ maximum of $65 \mathrm{ng} \mathrm{I}-\mathrm{TEQ} / \mathrm{Nm}^{3}$ is obtained. 
This is calculated considering the worst conditions in which a maximum production of dioxin and furan is achieved, and with no elimination of pollutants neither in the APC devices nor in the cyclones. Taking into account that the average PCDD/Fs emission measured during the sampling is approx. $5 \mathrm{pg} \mathrm{I}-\mathrm{TEQ} / \mathrm{Nm}^{3}$, i.e. $0.00725 \%$ of the calculated production in the burner.

\section{ACKNOWLEDGEMENTS}

Support for this work was provided by CEMEX ESPAÑA, S.A., a company owned by the CEMEX group (http://www.cemex.com). Authors acknowledge the financial support for this work provided by PROMETEO/2009/043/FEDER and ACOMP2010/075 of Generalitat Valenciana (Spain) and CTQ2008-05520 (Spanish MCI).

\section{LITERATURE CITED}

1. Rodrigues, F. A.; Joekes, I., Cement industry: sustainability, challenges and perspectives. Environmental Chemistry Letters 2010, 1-16.

2. Garg, A.; Smith, R.; Hill, D.; Simms, N.; Pollard, S., Wastes as cofuels: The policy framework for solid recovered fuel (SRF) in Europe, with UK implications. Environmental Science and Technology 2007, 41, (14), 4868-4874.

3. Ozkan, A.; Banar, M. In Refuse derived fuel (RDF) utilization in cement industry by using Analytic Network Process (ANP), 2010; 2010; pp 769-774.

4. Rovira, J.; Mari, M.; Nadal, M.; Schuhmacher, M.; Domingo, J. L., Partial replacement of fossil fuel in a cement plant: Risk assessment for the population living in the neighborhood. Science of the Total Environment 2010, 408, (22), 5372-5380.

5. Conesa, J. A.; Galvez, A.; Mateos, F.; Martin-Gullon, I.; Font, R., Organic and inorganic pollutants from cement kiln stack feeding alternative fuels. Journal of Hazardous Materials 2008, 158, (2-3), 585-592.

6. Rowell, R. M.; Rowell, J. K.; Young, R. A., Paper And Composites From Agrobased Resources. CRC Press: 1996.

7. TAPPI, a-, b- and g-cellulose in pulp. In TAPPI Press: Atlanta, US, 1978.

8. TAPPI, Preparation of extractive free wood. In TAPPI Press: Atlanta, US, 1978.

9. TAPPI, Acid-insoluble in wood and pulp. In TAPPI Press: Atlanta, US, 1978. 
10. Barneto, A. G.; Carmona, J. A.; GÃilvez, A.; Conesa, J. A., Effects of the composting and the heating rate on biomass gasification. Energy and Fuels 2009, 23, (2), 951-957.

11. Fullana, A.; Font, R.; Conesa, J. A.; Blasco, P., Evolution of products in the combustion of scrap tires in a horizontal, laboratory scale reactor. Environmental Science and Technology 2000, 34, (11), 2092-2099.

12. Aracil, I.; Font, R.; Conesa, J. A., Semivolatile and volatile compounds from the pyrolysis and combustion of polyvinyl chloride. Journal of Analytical and Applied Pyrolysis 2005, 74, (1-2), 465-478.

13. Conesa, J. A.; Fullana, A.; Font, R., Dioxin production during the thermal treatment of meat and bone meal residues. Chemosphere 2005, 59, (1), 85-90.

14. Conesa, J. A.; Font, R.; Fullana, A.; Martin-Gullon, I.; Aracil, I.; Galvez, A.; Molto, J.; Gomez-Rico, M. F., Comparison between emissions from the pyrolysis and combustion of different wastes. Journal of Analytical and Applied Pyrolysis 2009, 84, (1), 95-102.

15. Xhrouet, C.; Pirard, C.; De Pauw, E., De novo synthesis of polychlorinated dibenzo-p-dioxins and dibenzofurans on fly ash from a sintering process. Environmental Science and Technology 2001, 35, (8), 1616-1623.

16. Altarawneh, M.; Dlugogorski, B. Z.; Kennedy, E. M.; Mackie, J. C., Mechanisms for formation, chlorination, dechlorination and destruction of polychlorinated dibenzo-p-dioxins and dibenzofurans (PCDD/Fs). Progress in Energy and Combustion Science 2009, 35, (3), 245-274.

17. Conesa, J. A.; Gálvez, A.; Font, R.; Fullana, A., Formation of pollutants at intermediate oxygen level in sewage sludge combustion. Organohalogen Compounds 2007, 69, 1317-1320.

18. Conesa, J. A.; Fullana, A.; Font, R., Tire pyrolysis: Evolution of volatile and semivolatile compounds. Energy and Fuels 2000, 14, (2), 409418.

19. Fullana, A.; Conesa, J. A.; Font, R.; Sidhu, S., Formation and destruction of chlorinated pollutants during sewage sludge incineration. Environmental Science and Technology 2004, 38, (10), 2953-2958.

20. Karstensen, K. H., Formation, release and control of dioxins in cement kilns. Chemosphere 2008, 70, (4), 543-560.

21. Morris, E. A.; Morita, K.; Jia, C. Q., Understanding the effects of sulfur on mercury capture from coal-fired utility flue gases. Journal of Sulfur Chemistry 2010, 31, (5), 457-475.

22. Fiedler, H.; Lau, C.; Eduljee, G., Statistical analysis of patterns of PCDDs and PCDFs in stack emission samples and identification of a marker congener. Waste Management and Research 2000, 18, (3), 283-292.

23. Abad, E.; Martínez, K.; Caixach, J.; Rivera, J., Polychlorinated dibenzo-p-dioxin/polychlorinated dibenzofuran releases into the atmosphere from the use of secondary fuels in cement kilns during clinker formation. Environmental Science and Technology 2004, 38, (18), 4734-4738.

24. Schuhmacher, M.; Domingo, J. L.; Garreta, J., Pollutants emitted by a cement plant: Health risks for the population living in the neighborhood. Environmental Research 2004, 95, (2), 198-206.

25. Fabrellas, B.; Ruiz, M. L.; Martinez, M. A.; De la torre, A., The Spanish dioxin inventory: Evaluation of dioxin and furan emissions generated in the Spanish cement sector during 2003-2004 period. The influence of the alternative fuels use. Cemento-Hormigon 2005, 76, 60-69. 
26. Oh, J. E.; Gullett, B.; Ryan, S.; Touati, A., Mechanistic relationships among PCDDs/Fs, PCNs, PAHs, CIPhs, and CIBzs in municipal waste incineration. Environmental Science and Technology 2007, 41, (13), 47054710.

27. Wurst, F.; Prey, T., Dioxin emissions when using alternative fuels in the cement industry. ZKG International 2003, 56, (4), 74-77.

28. Liske, Y. M.; Kapila, S.; Spreng, A. C.; Schreiber, R. J., An assessment of polychlorinated dibenzo-para-dioxins and furans in raw materials for cement plant. Organohalogen Compounds 1996, 28, 249-254. 29. Sidhu, S.; Kasti, N.; Edwards, P.; Dellinger, B., Hazardous air pollutants formation from reactions of raw meal organics in cement kilns. Chemosphere 2001, 42, (5-7), 499-506.

30. Gossman, D., Factors influencing emissions levels of PCDD/PCDFs from cement kilns. Hazardous Waste Combustors. In Specialty conference. Air and Waste Management Association, 2001.

31. Yang, H. H.; Lee, W. J.; Chen, S. J.; Lai, S. O., PAH emission from various industrial stacks. Journal of Hazardous materials 1998, 60, (2), 159-174.

32. Achternbosch, M.; Bräutigam, K. R.; Hartlieb, N.; Kupsch, C.; Richers, U.; Stemmermann, P., Impact of the use of waste on trace element concentrations in cement and concrete. Waste Management and Research 2005, 23, (4), 328-337.

33. Gullett, B. K.; Bruce, K. R.; Beach, L. O., The effect of metal catalysts on the formation of polychlorinated dibenzo-p-dioxin and polychlorinated dibenzofuran precursors. Chemosphere 1990, 20, (10-12), 1945-1952.

34. Gullett, B. K.; Lemieux, P. M., Role of combustion and sorbent parameters in prevention of polychlorinated dibenzo-p-dioxin and polychlorinated dibenzofuran formation during waste combustion. Environmental Science and Technology 1994, 28, (1), 107-118.

35. Gullett, B. K.; Ragnunathan, K., Reduction of coal-based metal emissions by furnace sorbent injection. Energy \& Fuels 1994, 8, (5), 10681076.

36. Oficemen http://www.oficemen.com/fabrica.asp?id rep $=22 \& f a b=13$. (8/02/2011), 


\section{LIST OF TABLES AND FIGURES}

Figure 1. Dioxins and furans in the horizontal laboratory reactor.

Figure 2. PCDD/Fs congener profile in the emissions of the cement kiln at the different experimental conditions.

Figure 3. PAHs emission in the cement kiln stack in the different series.

Figure 4. Heavy metal emission in the cement kiln stack in the different series.

Figure 5. Principal component analysis of the heavy metal emission correlated with the amounts of different fuels used in the cement kiln.

Table 1. SRF characterization

Table 2. Cement kiln feeding rates of the different fuels used during sampling, percentage of fuel substituted by SRF and pollutant sampled.

Table 3. Average values of gas composition in the different series. 


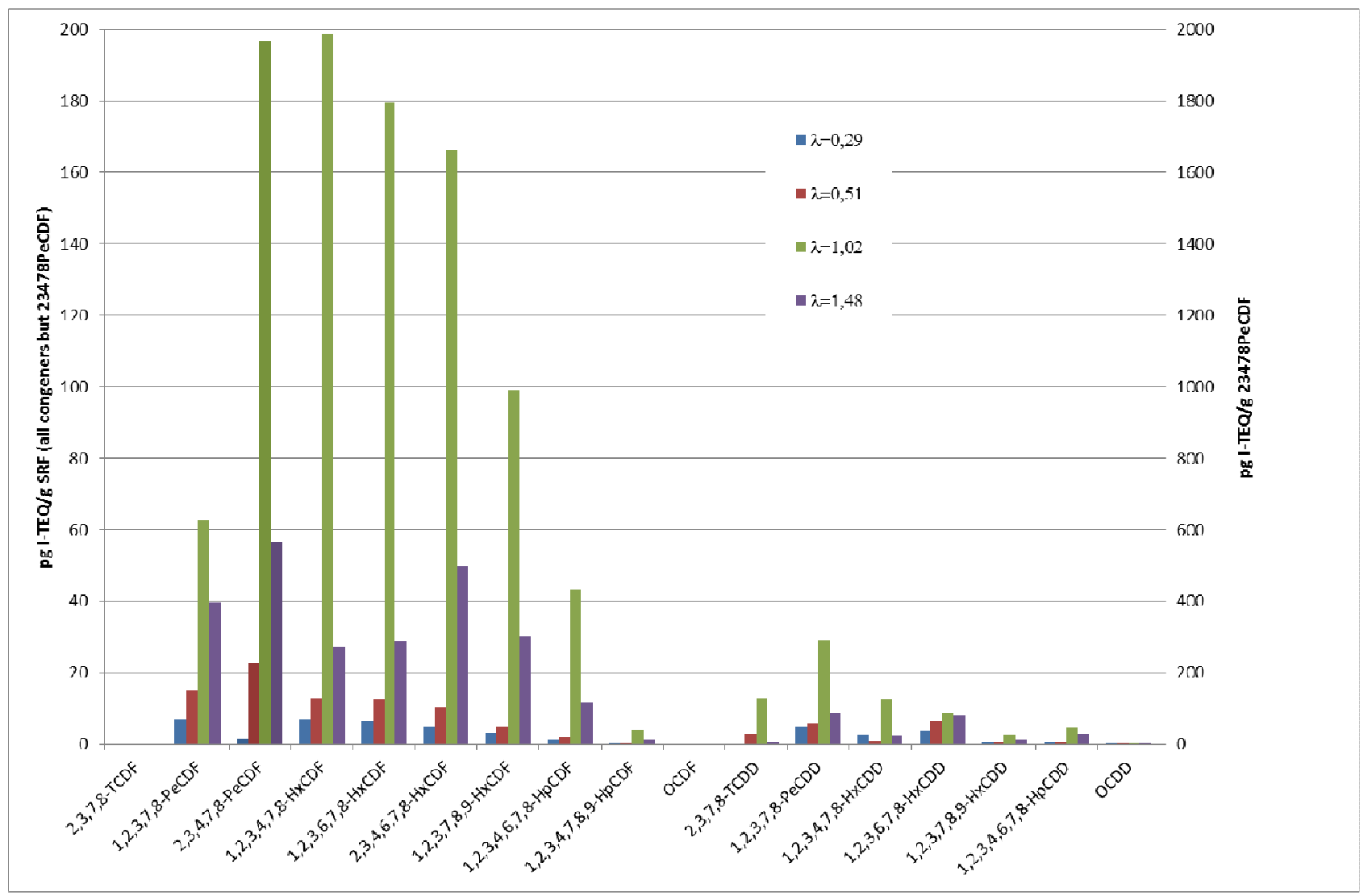

Figure 1. Dioxins and furans in the horizontal laboratory reactor. 


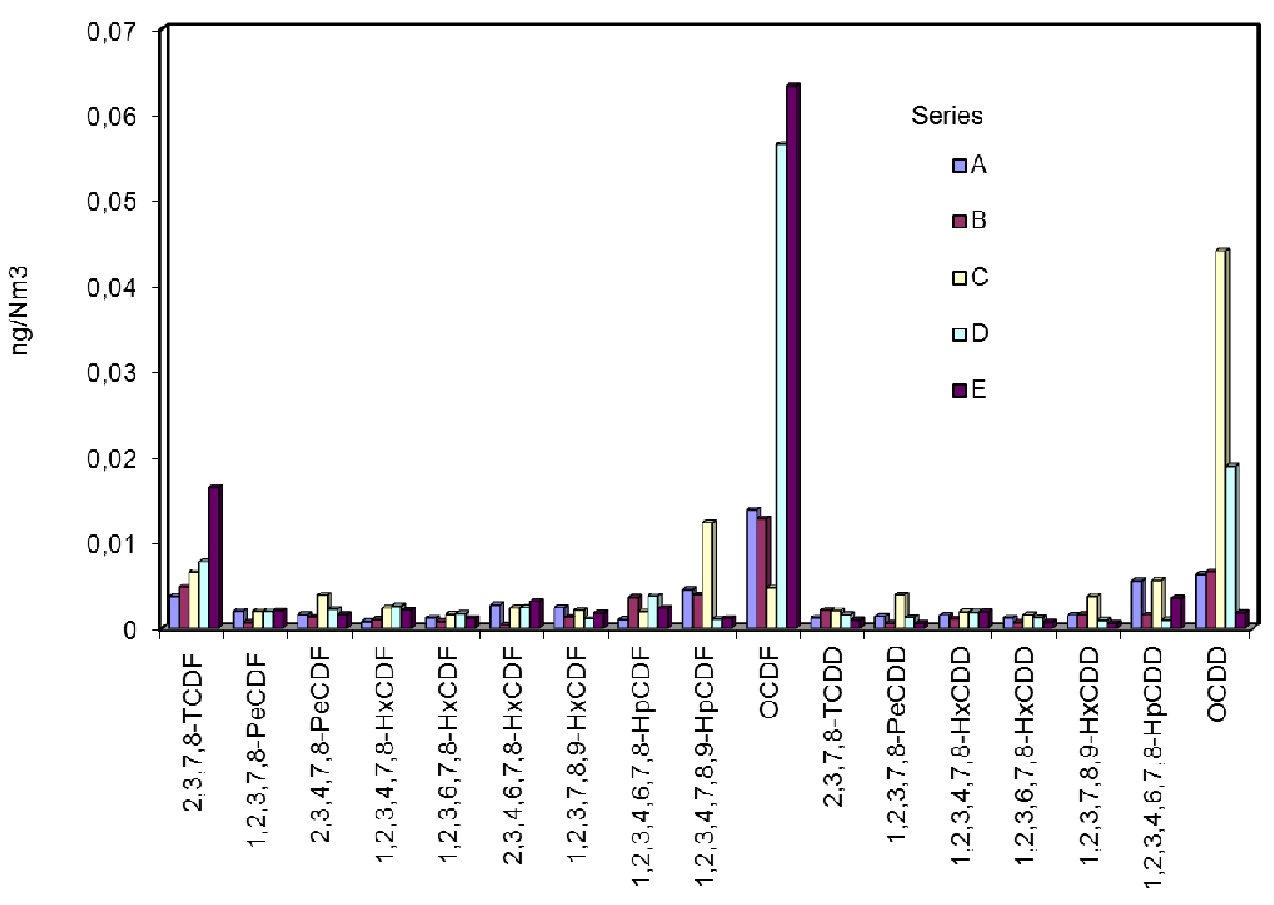

Figure 2. PCDD/Fs congener profile in the emissions of the cement kiln at the different experimental conditions. 


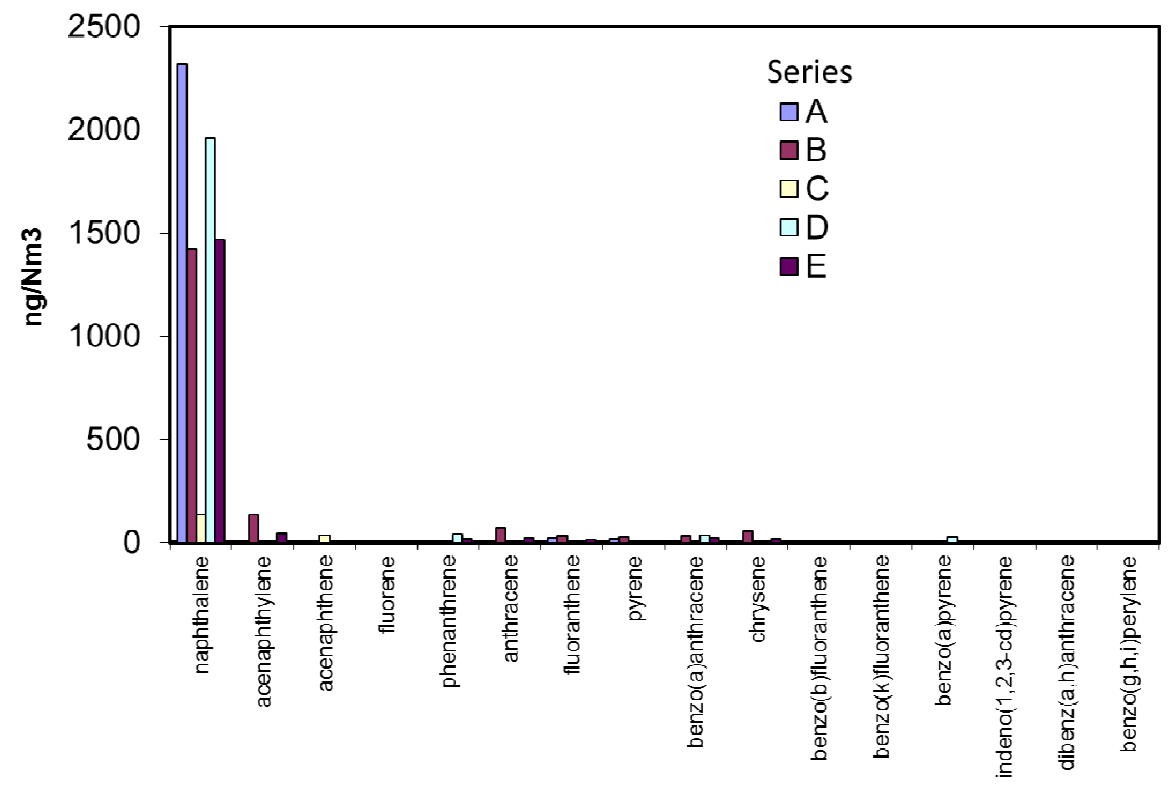

Figure 3. PAHs emission in the cement kiln stack in the different series. 


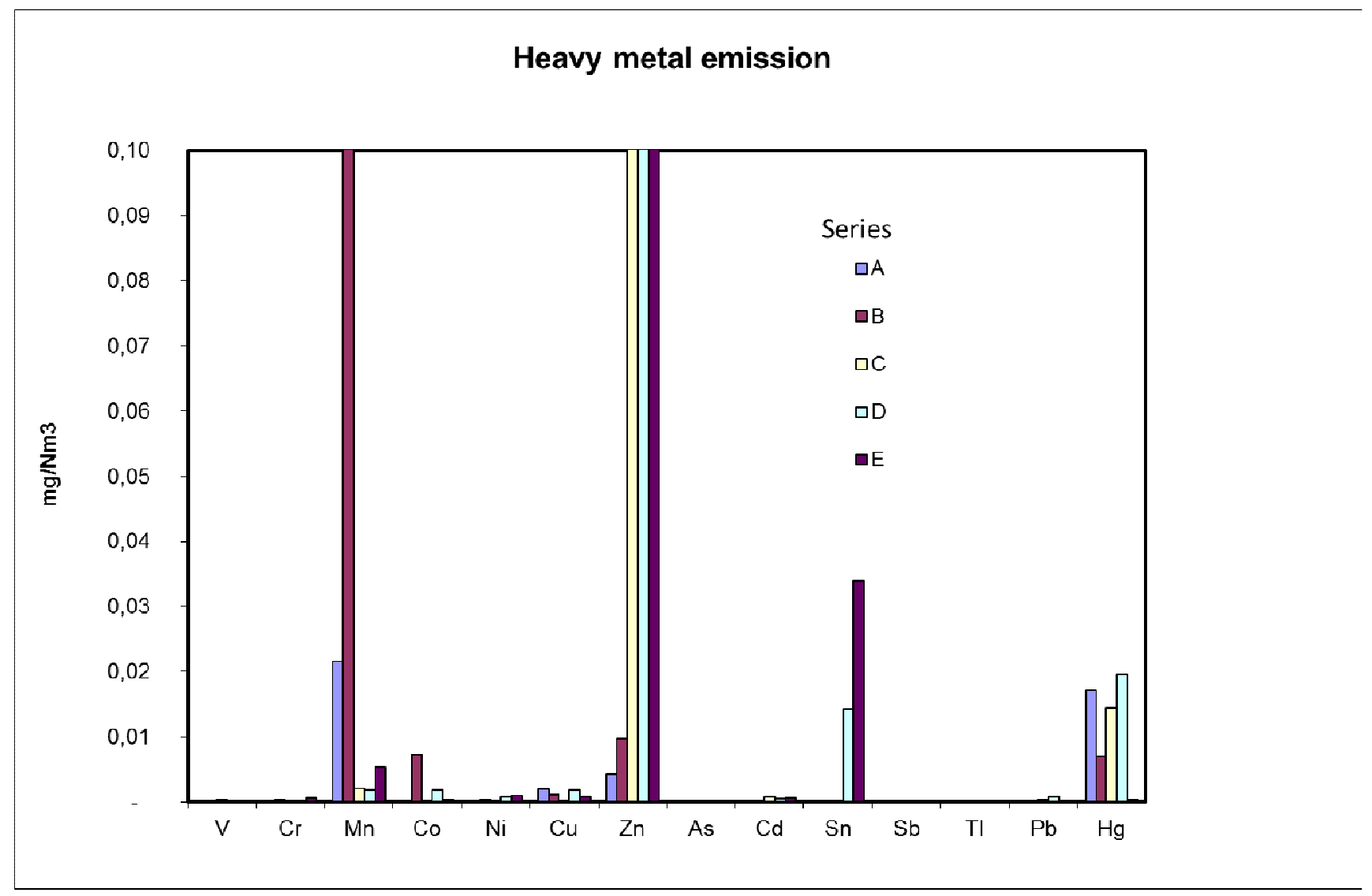

Figure 4. Heavy metal emission in the cement kiln stack in the different series. 


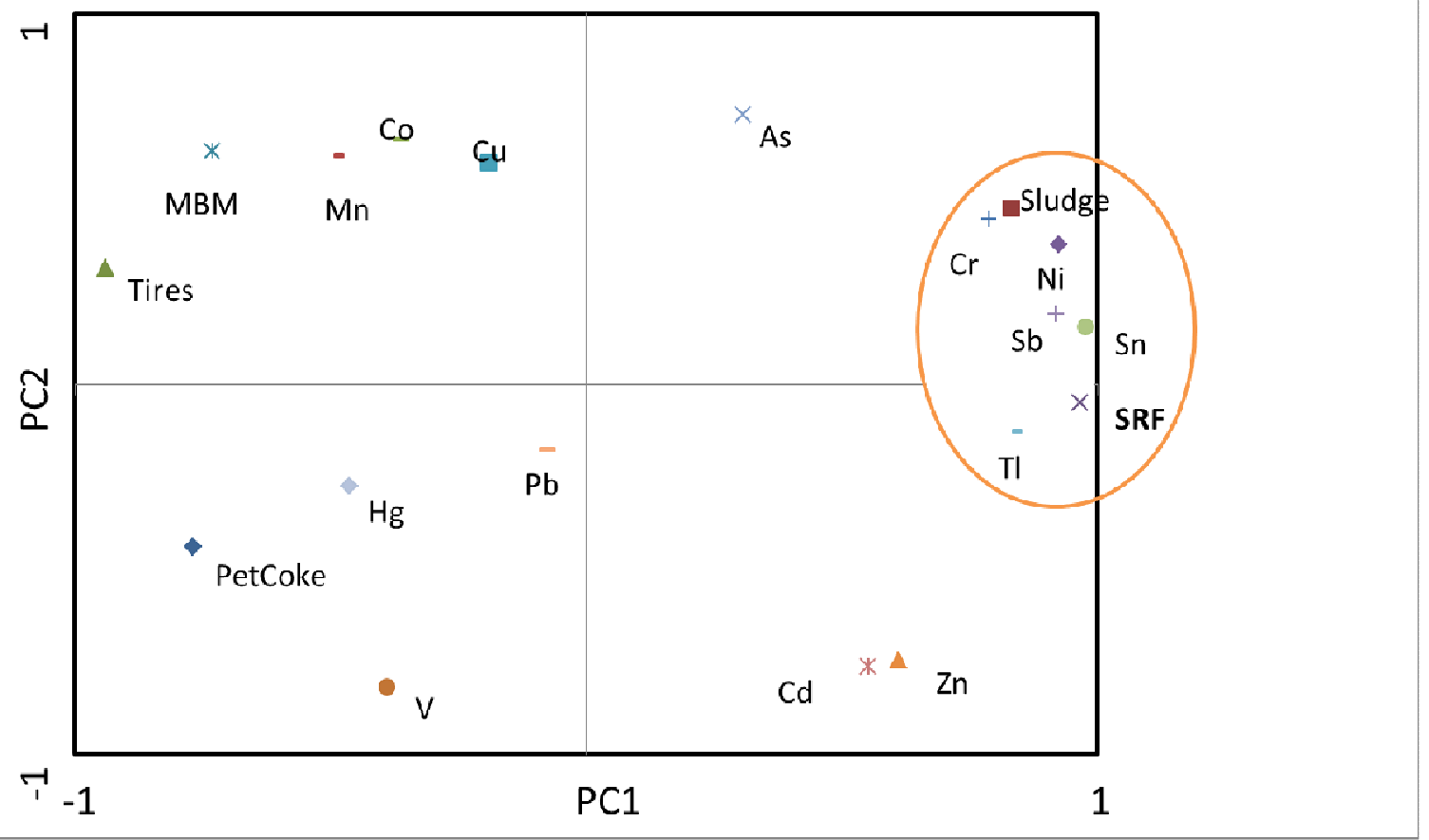

Figure 5. Principal component analysis of the heavy metal emission correlated with the amounts of different fuels used in the cement kiln. 


\begin{tabular}{|c|c|c|c|c|c|}
\hline \multicolumn{6}{|c|}{ Solid Recovered Fuel } \\
\hline Humidity & \multicolumn{2}{|c|}{$16.7 \%$ weight } & \multicolumn{2}{|c|}{$\%$ biomass in SRF } & 86.5 \\
\hline Net calorific value & \multicolumn{2}{|c|}{$4240 \mathrm{kcal} / \mathrm{kg}$} & \multicolumn{2}{|c|}{$\%$ Lignin in biomass } & 31.3 \\
\hline $\mathrm{SO}_{4}^{2-}$ & 3926 & $\mathrm{mg} / \mathrm{Kg}$ & \multicolumn{2}{|c|}{$\%$ Cellulose in biomass } & 61.1 \\
\hline $\mathrm{Cl}^{-}$ & 2298 & $\mathrm{mg} / \mathrm{kg}$ & \multicolumn{2}{|c|}{$\%$ Hemicelulose in biomass } & 7.5 \\
\hline \multicolumn{6}{|c|}{ Elemental analysis (wt. \%) } \\
\hline $\mathbf{H}$ & 5.33 & $\mathbf{N}$ & 1.07 & $O$ (by diff.) & 42.39 \\
\hline C & 40.85 & $\mathbf{s}$ & 0.15 & Ash & 10.2 \\
\hline \multicolumn{6}{|c|}{ METALS (mg/kg) } \\
\hline $\mathbf{v}$ & 15 & As & 25 & Sb & 32 \\
\hline $\mathbf{C r}$ & 78 & Cd & 2 & TI & 4 \\
\hline Mn & 354 & Sn & 18 & $\mathbf{H g}$ & 0.2 \\
\hline Co & 4 & $\mathbf{N i}$ & 52 & Te & 2 \\
\hline $\mathbf{Z n}$ & 658 & $\mathrm{Cu}$ & 240 & $\mathbf{P b}$ & 235 \\
\hline \multicolumn{6}{|l|}{ PAH (mg/kg) } \\
\hline naphthalene & & $4.23 \cdot 10^{-2}$ & fluoranthene & & $4.52 \cdot 10^{-2}$ \\
\hline acenaphtylene & & nd & pyrene & & $1.18 \cdot 10^{-2}$ \\
\hline acenaphthene & & nd & \multicolumn{2}{|c|}{ benzo(a)anthracene } & $4.47 \cdot 10^{-2}$ \\
\hline fluorene & & $1.34 \cdot 10^{-2}$ & chrysene & & $4.46 \cdot 10^{-2}$ \\
\hline phenanthrene & & $1.71 \cdot 10^{-2}$ & \multicolumn{2}{|c|}{ benzo(b)fluoranthene } & nd \\
\hline anthracene & & nd & \multicolumn{2}{|c|}{ benzo(k)fluoranthene } & nd \\
\hline \multicolumn{2}{|c|}{ Dibenz(a,h)anthracene } & nd & Benzo(a)pyrene & & nd \\
\hline \multicolumn{2}{|c|}{ Benzo(g,h,i)perylene } & nd & \multicolumn{2}{|c|}{ Indene $(1,2,3-\mathrm{cd})$ pyrene } & nd \\
\hline \multicolumn{6}{|l|}{ PCDD/Fs (pg/g) } \\
\hline 2378-TCDF & & 2.98 & 2378-TCDD & & 0.30 \\
\hline 12378-PeCDF & & 1.78 & 12378-PeCDD & & 2.22 \\
\hline 23478-PeCDF & & 3.47 & 123478-HxCDD & & 1.37 \\
\hline 123478-HxCDF & & 4.18 & 123678-HxCDD & & 3.53 \\
\hline 123678-HxCDF & & 3.24 & 123789-HxCDD & & 0.16 \\
\hline 234678-HxCDF & & 4.82 & 1234678-HpCDD & & 109.65 \\
\hline 123789-HxCDF & & 2.07 & OCDD & & 1655.4 \\
\hline 1234678-HpCDF & & 21.08 & & & \\
\hline 1234789-HpCDF & & 3.23 & Total pg I-TEQ/g & & 8.61 \\
\hline OCDF & & 139.01 & & & \\
\hline
\end{tabular}


Table 2. Cement kiln feeding rates of the different fuels used during sampling, percentage of fuel substituted by SRF and pollutant sampled.

\begin{tabular}{|c|c|c|c|c|c|c|c|}
\hline Run series & $\begin{array}{c}\text { Petroleum } \\
\text { coke } \\
(\mathbf{k g} / \mathbf{h})\end{array}$ & $\begin{array}{c}\text { Sewage } \\
\text { sludge } \\
(\mathbf{k g} / \mathbf{h})\end{array}$ & $\begin{array}{c}\text { Tires } \\
(\mathrm{kg} / \mathrm{h})\end{array}$ & $\begin{array}{c}\text { Meat } \\
\text { bone } \\
\text { meals } \\
(\mathrm{kg} / \mathrm{h})\end{array}$ & $\begin{array}{c}\mathrm{SRF} \\
(\mathrm{kg} / \mathrm{h})\end{array}$ & $\begin{array}{c}\text { \% SRF } \\
\text { (energy) }\end{array}$ & Sampling \\
\hline \multirow{3}{*}{$\mathbf{A}$} & 8400 & 500 & 1330 & 3500 & 0 & $0 \%$ & PCDD/Fs \\
\hline & 4950 & 0 & 1125 & 2900 & 0 & $0 \%$ & $\mathrm{HCl} / \mathrm{HF}$ \\
\hline & 8950 & 0 & 1200 & 830 & 0 & $0 \%$ & $\mathrm{HM}$ \\
\hline \multirow{3}{*}{ B } & 6250 & 375 & 1400 & 3100 & 3000 & $13 \%$ & $\mathrm{PCDD} / \mathrm{Fs}$ \\
\hline & 5870 & 500 & 1370 & 4000 & 3000 & $13 \%$ & $\mathrm{HCl} / \mathrm{HF}$ \\
\hline & 5375 & 0 & 1100 & 2580 & 3000 & $15 \%$ & $\mathrm{HM}$ \\
\hline \multirow{3}{*}{ C } & 8040 & 0 & 1080 & 0 & 6000 & $23 \%$ & $\mathrm{PCDD} / \mathrm{Fs}$ \\
\hline & 8400 & 0 & 540 & 0 & 6000 & $23 \%$ & $\mathrm{HCl} / \mathrm{HF}$ \\
\hline & 8330 & 0 & 580 & 0 & 6000 & $24 \%$ & $\mathrm{HM}$ \\
\hline \multirow{3}{*}{ D } & 7960 & 300 & 1440 & 300 & 12000 & $36 \%$ & $\mathrm{PCDD} / \mathrm{Fs}$ \\
\hline & 6520 & 1170 & 200 & 0 & 12000 & $43 \%$ & $\mathrm{HCl} / \mathrm{HF}$ \\
\hline & 5750 & 750 & 370 & 0 & 12000 & $46 \%$ & $\mathrm{HM}$ \\
\hline \multirow{3}{*}{$\mathbf{E}$} & 2500 & 250 & 0 & 0 & 16000 & $74 \%$ & $\mathrm{PCDD} / \mathrm{Fs}$ \\
\hline & 2000 & 1000 & 290 & 0 & 15000 & $73 \%$ & $\mathrm{HCl} / \mathrm{HF}$ \\
\hline & 2200 & 1000 & 290 & 0 & 15000 & $74 \%$ & $\mathrm{HM}$ \\
\hline
\end{tabular}


Table 3. Average values of gas composition in the different series, and their standard deviation for three sampling days.

\begin{tabular}{|c|c|c|c|c|c|}
\hline Series & A & B & C & D & E \\
\hline $\mathbf{O}_{2}(\boldsymbol{\%})$ & $11.1 \pm 1.1$ & $10.2 \pm 0.4$ & $9.8 \pm 0.1$ & $12.2 \pm 0.2$ & $13.5 \pm 0.9$ \\
$\mathbf{S O}_{\mathbf{2}}(\mathbf{p p m})$ & $116 \pm 32$ & $92 \pm 42$ & $67 \pm 17$ & $62 \pm 25$ & $21 \pm 20$ \\
$\mathbf{N O}(\mathbf{p p m})$ & $28 \pm 12$ & $17 \pm 9$ & $23 \pm 10$ & $20 \pm 13$ & $19 \pm 8$ \\
$\mathbf{N O}(\mathbf{p p m})$ & $651 \pm 96$ & $629 \pm 100$ & $687 \pm 154$ & $426 \pm 99$ & $312 \pm 62$ \\
$\mathbf{C O}(\boldsymbol{\%})$ & $6.1 \pm 0.1$ & $6.3 \pm 0.0$ & $7.0 \pm 0.0$ & $5.4 \pm 0.1$ & $4.9 \pm 0.2$ \\
$\mathbf{C O}(\mathbf{p p m})$ & $113 \pm 23$ & $204 \pm 60$ & $488 \pm 79$ & $388 \pm 47$ & $275 \pm 52$ \\
Temperature ('C) & $164 \pm 3.3$ & $164 \pm 2.2$ & $147 \pm 1.7$ & $149 \pm 1.2$ & $162 \pm 1.2$ \\
\hline
\end{tabular}

